\title{
A REVIEW ON GELCOAT USED IN LAMINATED COMPOSITE STRUCTURE
}

\author{
Yuhazri M.Y ${ }^{1}$, Haeryip Sihombing ${ }^{2}$, Muhammad Zaimi Z.A ${ }^{3}$, Nilson G.C.H ${ }^{4}$ \\ ${ }^{1}$ Faculty of Manufacturing, Universiti Teknikal Malaysia Melaka, Malaysia \\ ${ }^{2}$ Faculty of Manufacturing, Universiti Teknikal Malaysia Melaka, Malaysia \\ ${ }^{3}$ Faculty of Manufacturing, Universiti Teknikal Malaysia Melaka, Malaysia \\ ${ }^{4}$ Faculty of Manufacturing, Universiti Teknikal Malaysia Melaka, Malaysia
}

\begin{abstract}
Gelcoat are widely used to provide exterior protection for the finished part of fiber reinforced composite material. It is a primary focus to achieve proper gelcoat film thickness because it is a critical control point for crack prevention which is able to increase mechanical strength and withstand harsh environment. The interface between the gelcoat and laminate composite is similarly imperative in deciding the mechanical performance of the composite by controls the reintroduction of stress into component. There are no specified standard to verified that how much gel-coat thickness required to produce certain product since mostly research only focus on the enhancement of composite orientation and fiber combination. The aim of this review is to gain an in depth understanding of exactly the effect of gel-coat thickness on laminate composite structure and strength
\end{abstract}

Keywords: Gelcoat, Thickness, Protection, Laminated, Composite.

\section{INTRODUCTION}

The mixture of thermoset resin like epoxy or polyester resin with hardener is known as gelcoat when the material immediately applied on the mould surface with a brush or spray to be the first external part before laminating process take place. The mixture ought to be applied on mould as fast as it can because generally the mixture may solidify. The quantity of epoxy utilized should be approximately equivalent to the weight of the glass fiber sheets while the quantity of hardener is approximately $1 \mathrm{wt} . \%$ [1] to $10 \mathrm{wt} . \%$ [2] of the weight of glass fiber sheets. The gelcoat applied is to guarantee a smooth external surface and for the assurance of fibers from immediate exposure to the environment. The procedure proceeds with the subsequent stacking with layers of reinforcement by the application of gelcoat.

Moreover, Karapappas [3] indicated gelcoat is a material used to provide a high-quality finish on the visible surface of a fiber-reinforced composite material. The most widely recognized gelcoat is focused on epoxy or unsaturated polyester resin with thoughtfulness regarding to Scholz [4], Keegan [5], Yardimcia [6]. Gelcoat is a modified resin which applied on mould surface in the liquid state. They are cured to form cross linked polymers and are subsequently backed with composite polymer matrices. Furthermore, Washer and Schmidt [7] asserted that gelcoat is a thick resin layer on the exterior surface of the laminate which can be applied through spraying or rolling application. The gelcoat also enhances fire protection of the beam and provides an additional barrier against moisture. Research done by Mouritz and Gibson [8] demonstrates a further issue is that numerous coatings, particularly those that are extremely good insulators but are extravagant. The cost of utilizing the coatings is increased further because they need to be bonded to the composite structure. Many composite applications oblige a gel-coated surface for cosmetic or durability reasons. The most common method of preparation is to paint or spray the mould tool, allow the coating to gel before laminating on the tacky surface. A layer of gelcoat is then sprayed on to the mould to form the outermost surface of the products. The gelcoat is allowed to cure for several hours however remains tacky so subsequent resin layers adhere better. Alternate layers of catalyzed polyester resin and reinforcement material are applied. Each reinforcement layer is wetted out with resin, and then rolled out to uproot air pockets. The procedure proceeds until the desired thickness is attained as highlighted by Dong [9].

Many current researchers like Gombos and Summerscales [10], Landowski [11], Salit [12] and Raghavendra [13] are more to use different gel-coating process or preparation method to fabricate low defect gelcoat in the mould. The main focus is on the performance of gelcoat on their outlined product especially particularly with respect to service period against harsh environment. The best author's knowledge stated that there still no experimental research done about the effect of gelcoat thickness on laminate structure and strength. Thus, this is a very exceptionally topic to be explored in detail to gain deep understanding on roles of different gelcoat thickness affect laminated structure and strength.

\section{GELCOAT}

Borsting [14] describes gelcoat is a material used to provide a high quality finish on the visible surface of the finished part of a fiber-reinforced composite material. Gelcoats are applied to moulds in the liquid state. They are cured to form cross-linked polymers and are subsequently backed up with 
composite polymer matrices, fiberglass or epoxy resin with glass fibers and mixtures of polyester resin. Fiber GlassEvercoat Corp [15] provide gelcoats typically consist of four classes of ingredients polymer, additives, filler, and reactive diluents. Curing stage may take certain period of time depending on such factors as working temperature, catalyst levels, mould shape and mould shape. Gel coat is best applied by spray application with a pressure pot or catalyst injection system. Gel coat also can be applied either using a standard paint gun with primer nozzle or prevail sprayer. There are also other method like brush and roller. It is important to achieve the proper thickness in the mostly stressed areas because thickness is a critical control point for crack prevention or other defects is mentioned by Lacovara [16].

Gelcoats must resist mechanical and thermal stresses encountered during the curing and de-moulding process. Gelcoat is designed to protect the exterior part of composite product and is painted after the product is removed from the mould as reported by Saltz [17]. Besides, Wright [18] showed that polyester gel coat is first sprayed onto the mould surface when built a polyester boat. The first layer of the laminate is applied to gel coat is not fully cured. The two layers theoretically cure together by chemical bond between them. Based on the information obtained from Fiber GlassEvercoat [15], there are three main categories of gelcoat.
Table 1 show coverage, cure times, application of gelcoat mentioned:

\subsection{Premium Laminating Gel Coat}

A premium quality laminating polyester gel coat that remains tacky between layers for easy re-coating. This airinhibited product requires the use of a mould release agent to seal off the air and ensure cure to a hard surface when used as a final coat.

\subsection{One Step Finish Gel Coat}

A premium quality finish polyester gel coat that cures to a hard surface. This gelcoat does not require the use of a mould release, but needs to be sanded between the layers to ensure proper adhesion.

\subsection{Polyester Gel Paste}

A premium quality finish polyester gel paste that cures to a hard surface. This material used to fill deep gouges or fill in the spots where the gel coat is damaged. This formula of thicker that the gel coat, and is ideal for applications where material build is necessary.

Table 1: Coverage, cure times, application suggestions by Fiber Glass-Evercoat [15]

\begin{tabular}{|l|l|c|c|}
\hline \multicolumn{1}{|c|}{ Product Number } & $\begin{array}{c}\text { Coverage per gallon } \\
\text { @ 0.25mm }\end{array}$ & $\begin{array}{c}\text { Working Time / } \\
\mathbf{2}^{\text {nd }} \text { Coat (minutes) }\end{array}$ & $\begin{array}{c}\text { Fully } \\
\text { Cured (hour) }\end{array}$ \\
\hline Premium Gel Coat & $\begin{array}{l}60 \text { sq. feet per } 1 \text { gallon } \\
\text { at } 0.5 \text { mm thickness }\end{array}$ & 17 to 30 & 4 to 6 \\
\hline One Step Finish Gel Coat & $\begin{array}{l}50 \text { sq. feet per } 1 \text { gallon } \\
\text { at } 0.5 \text { mm thickness }\end{array}$ & 15 to 30 & 4 to 6 \\
\hline
\end{tabular}

*Note: $0.5 \mathrm{~mm}$ thickness is equals to 20 sheets of paper.

\section{GELCOAT THICKNESS}

Lacovara [16] proposed that method of application and conditions of entire process are the major influence on the integrity of gel coat film. Gelcoat film thickness is the most important control point in the process. For most gelcoats, the range of specified wet applied thickness is between $0.4 \mathrm{~mm}$ to $0.6 \mathrm{~mm}$. This range may vary slightly with specially formulated products. However, there is a specific optimum thickness range for each formulation of gelcoat required by the manufacturer of the product. Variations in gel coat thickness can cause several problems ranging from under cure due to thin gelcoat and cracking cause by thick gelcoat. Another critical view to consider is the average thickness of gel coat on a part may not prevent cracking. For example, if a part averages $0.45 \mathrm{~mm}$ thick, but the corner areas are 0.66 $\mathrm{mm}$, localized cracking may occur over thick areas. It is important to achieve the proper thickness in the most highly stressed areas of a part because thickness is a critical control point for crack prevention, so the spray process are temporary rated as the best method for gel coat application.
Saltz [17] summarized that gelcoats can be applied to mould by using multiple applications but the most suitable method via spray technology with a preferred thickness between $0.25 \mathrm{~mm}$ to $0.50 \mathrm{~mm}$. Gelcoats applied too thinly will undercure, while those applied too thickly will crack when exposed to flexing forces. Occasionally, gel coats are handapplied to surfaces with a brush. Specialized gelcoats with high levels of durability are sometimes used to manufacture moulds which in turn are used to fabricate composite products. Such gelcoats must resist mechanical and thermal stresses encountered during the curing and de-moulding processes. A primer gel coat is a specialized gel coat designed to protect the exterior of a composite product and is painted after the product is removed from the mould. Table 2 show the different gelcoat thickness use by the previous researcher in different application. 
Table 2: Variation of gelcoat thickness in previous research

\begin{tabular}{|l|c|c|c|}
\hline \multicolumn{1}{|c|}{ Application } & Gel coat Thickness (mm) & Layers Applied & References \\
\hline Fiberglass boat & 0.30 to 0.56 & - & {$[19]$} \\
\hline Transport, chemical plant, energy systems, pipelines & 0.50 & - & {$[20]$} \\
\hline Fiber-reinforced composite material & 0.20 to 0.50 & - & {$[21]$} \\
\hline Glass fibre reinforced polyester resin moulded & 0.20 to 0.60 & 2 & {$[22]$} \\
\hline Invention hybrid resins & thick section of $0.76 \& 0.38$ & 2 & {$[23]$} \\
\hline
\end{tabular}

\section{GELCOATING PROCESS}

Derek [24] explain gelcoating process is apply the epoxy or polyester type gelcoat material to provide a high-quality finish on the visible surface of a fiber-reinforced composite material. When it is sufficiently cured, it will be removed from the mould and gelcoated surface are presented. It is usually pigmented to provide a glossy and coloured surface to improve the aesthetic appearance of the product.

\subsection{Brush and Roller}

BUFA Gelcoat Plus Corporation [22] analyzed that using brush is the easiest method to apply gelcoats. Brush method have the advantage in very good air release and low emission of styrene. The gelcoat's pigmentation should be adjusted to make brush strokes not visible. Ideally, each two layers of $300 \mu \mathrm{m}$ are applied. The second layer is applied after the first has initially cured and does not open when the second is brushed on. However, it is not easy to maintain an even layer thickness over the whole piece with this application method. A special hand application rolling method is mainly used for the production of large moulded articles with large surfaces to achieve a relatively short coating time. However, not every gelcoat in brush consistency is suitable for rolling and special formulations must often be selected for large surface objects.

\subsection{Spray}

Saltz [17] proved that spray application is better than brushing. Gelcoats that are optimized in regard to viscosity and air release are available for spraying. A lot of air brought into the gel coat by spraying have caused emission of styrene is increased at the same time. Spray technologies separate resin and gelcoat liquids into a fine mist by forcing the liquid under high pressure through an elliptical orifice, by bombarding a liquid stream. The net result is some overspray that reduces the transfer efficiency of the material sprayed onto moulds. The gun should be led perpendicular to the surface of the mould, spraying length-wise and crosswise at a distance of approximate $0.5 \mathrm{~m}$, depending on the material used and size of the spray nozzle. BUFA Gelcoat Plus Corporation [22] indicated to minimize the emission of styrene and optimize air release, the droplets formed when spraying should be as large as possible and spraying pressure should very low. The easiest spraying method is by using cup guns. Peroxide is added to a maximum of $2.5 \mathrm{~kg}$ of gelcoat in the cup and sprayed onto the mould with compressed air. Cup guns are used for smaller moulded articles when colours are changed often.

\subsection{A Comparison of the Gelcoating Process}

Scott Bader Corp. [25] researched about the comparison in between the brush roller and spray application. In term of achieving required film thickness, brush gelcoat users usually apply two layers of gel coat. This allows a minimum film thickness to be achieved across the whole moulding, but this can lead to excessive film thickness in some areas. In the other hand, double gelling is not common practice for spray application. Film thickness is built by spray a number of passes over the same area, and care is needed to achieve the correct wet film thickness evenly across the whole mould. With a good fan pattern, it is possible to achieve the required film thickness evenly. By considering the equipment costs, brush gelcoat application appear to be very low. Reuse of brushes and buckets can maintain minimum costs. However caution procedures must be taken to ensure that this doesn't prompt to contamination issues for cases like with different colour gelcoat cleaning solutions. Expenses of disposables can be extensive. While initial outlay for a good quality spray machine is high. The machine also needs ongoing maintenance and servicing. However, a well maintained spray gun can be run at low cost. Factors of porosity and pinholes can occur in any brush gelcoat if the application is poor. Skilled operators are required to ensure that this is minimized. Most air release systems require the shear applied through brushing to activate the air release. Optimization of the spray machine settings and skilled operators are required to minimize porosity. Most commercially available spray formulations contain filler to minimize the tendency for micro-porosity to occur. If the gelcoat is poorly applied, and the film thickness varies, then ultraviolet degradation can be patchy. Due to the viscosity of a gelcoat designed for brush application is higher than for spray application, less styrene and other monomer is required in the system. Conversely, more monomer is required to achieve a viscosity that is sprayable. The volatile organic compound is also atomized by the process of spraying. As with brush gelcoat, choice of gelcoat base and pigments used for colour play a hugely significant part.

\section{INFLUENCE OF MEKP IN GELCOAT}

Lacovara [16] studied the gelcoat cracking, along with fading or chalking problems, are the nemesis of product warranties for much of the fiber reinforced polymer composites industry. While color change and chalking problems may be addressed to some extent by proper end user maintenance. Mild surface issues such as chalking or fading may be remedied by buffing and waxing, however gelcoat cracking involves a repair. The issue may extend from cosmetic hairline cracks to cracks that stretch into the laminate and portend a structural imperfection. 
According to Aird [26], there are three main problems faced in preparing gel coat. Firstly, the fluid passage and orifices in ordinary paint guns are too small to deal with a viscous liquid like gel coat. Acetone will reduce the viscosity of gel coat sufficiently to allow it to be sprayed with a conventional paint gun, but some of the solvent will remain trapped in the plastic as it cures, leaving soft coating. Dilution with styrene is better, as the styrene will cross-link with the polyester but excess styrene will cause brittle gel coat. Secondly, gel coat needs to be catalyzed in order to cure. But if the catalyst is included in the plastic being sprayed, it becomes essential to completely dismantle the gun for cleaning after each use, before the gel coat has cured. Finally, most inexpensive general purpose paint guns are made from materials that are not resistant to some of the components in gel coat. The Methyl Ethyl Ketone Peroxide (MEKP) catalyst is particularly corrosive, but the inert fillers can cause rapid erosion of the metering needle and orifice.

The ratio of catalyst resin is regulated is depends on the nature of the spraying equipment. It is very important to keep the proportion of catalyst within the range specified by the gel coat supplier typically from $1 \%$ to $2.5 \%$ do supported by Jawahar [27]. Insufficient catalyst will slow the cure of the gel coat, requiring a long time before ready to be laminated on. If hold up in production, the surface become contaminated with dust or airborne moisture. Inadequate catalyst will result in an incomplete cure that the resin gels begins to cure. During hot environment when the proportion of catalyst is cut back to allow increased working time and to avoid excessive exothermal. Speed up the curing process of any thermosetting resin with heat, but not overdo it. No blow hot air directly on the surface of any curing polyester including gel coat. This will cause styrene evaporation, resulting in a soft rubbery surface. Excess catalyst may hasten the cure that the gel coat shrinks excessively, pulling away from the mould and leaving sinks in the surface of finished part. Too much catalyst cause pinholes in the gel coat, because there is insufficient time for the escape of air entrained in the spray. An extreme surplus of catalyst will cause overheating and blistering that will make the part useless, and may damage the mould is approach by Aird [26].

\section{CURING OF GELCOAT}

Nielsen [28] discovered curing is the term given to describe polymer solidification during cross-linking. During curing, thermoset resins evolve from liquids of low molecular weight to solids with fully developed three dimension crosslinked networks. Cross-links can be formed by chemical reactions that are initiated by curing agents, temperature, pressure or radiation. The cross-linking and branching action results in a loss of polymers ability to move as individual polymer chains, consequently resulting an increase in viscosity. Initially the resin viscosity drops upon the application of maximum heat flow and then begins to increase again as the chemical reactions commence between average length and degree of cross-linking. This point is known as the gelation point and is characterized by the material transition from a viscous liquid to a rubbery solid exhibiting viscoelastic-type behavior. Consequently, an increase in stiffness is experienced after the onset of gelation allowing the material to be able to sustain strains and stresses.

Osman [29] found that curing behavior of unsaturated polyester is due to different concentration of styrene monomer which is measured via viscosity, gel time, and maximum exothermal temperature. The curing reaction is a very complicated process that is affected by many different factors, such as weather, humidity, resin uniformity, conditions of ingredients as they are stored and equipment conditions. The process of cure of thermosets consists of two main stages that are the heating period of liquid resin either pure or in the form of composites with fillers and the cure reaction in the mould. The primary structure of the master model is formed by the energy balance which consider several factors which are the accumulation of heat in the composite, the heat generated by the chemical reaction, the heat conduction in the material, and the heat dissipation at the composite skin is done by Kosar and Gomzi [30]. Table 3 show the different amount of catalyst used in different polyester resin including cross linking agent.

Table 3: Polyester resin, catalyst, and cross linking agent

\begin{tabular}{|c|c|c|c|}
\hline $\begin{array}{c}\text { Thermoset } \\
\text { Resin }\end{array}$ & $\begin{array}{l}\text { Catalyst/ } \\
\text { Initiator } \\
(\text { MEKP) }\end{array}$ & $\begin{array}{c}\text { Cross } \\
\text { Linking } \\
\text { Agent } \\
\text { (Styrene } \\
\text { Monomer) }\end{array}$ & References \\
\hline $\begin{array}{l}\text { Phthalic } \\
\text { Anhydride, } \\
\text { Maleic } \\
\text { Anhydride } \\
\text { Propylene } \\
\text { Glycol }\end{array}$ & $\begin{array}{c}\text { Volume } \\
\text { fraction } 50 \\
\% \text { solution }\end{array}$ & $\begin{array}{c}\text { Weight } \\
\text { fraction } 30 \% \\
\text { solution }\end{array}$ & {$[30]$} \\
\hline $\begin{array}{l}\text { Unsaturated } \\
\text { Polyester }\end{array}$ & $\begin{array}{l}\text { MEKP, } \\
\text { Dimethyl } \\
\text { Aniline } \\
\text { (DMA) }\end{array}$ & $\begin{array}{l}(60 \%+40 \%) \\
(50 \%+50 \%) \\
(40 \%+60 \%)\end{array}$ & [29] \\
\hline $\begin{array}{l}\text { Epoxy } \\
\text { Polyester } \\
\text { Clear Powder } \\
\text { Coatings }\end{array}$ & - & - & [31] \\
\hline $\begin{array}{l}\text { Propylene } \\
\text { Glycol, } \\
\text { Isophthalic } \\
\text { Acid. }\end{array}$ & - & 1460 grams & [32] \\
\hline Bushepol & 1.5 MEKP & - & {$[33]$} \\
\hline $\begin{array}{l}\text { Unsaturated } \\
\text { Polyester }\end{array}$ & $1 \%$ MEKP & $750 \mathrm{ml}$ & [34] \\
\hline
\end{tabular}

\section{GELCOAT DEFECTS}

Most gelcoat defects occur while moulding but are not apparent until after release from the mould. By then the moulding is painfully expensive to scrap just because of 
cosmetic blemishes. A good moulder will solve trouble to make high quality gelcoat. It is time consuming but can make the defect invisible with better handling skill. Although often reappear later, unless the guarantee has expired due to weathering and age.

Plessis [35] performed experimental investigation on various type of defects. Wrinkles look like centipede or dried apple and mostly are caused by the resin, lay up process or second gel coat is being applied earlier and softening the first layer before it has properly set also if the gel coat is too thin. The treatment is to fill with gel coat or colored filler and polish to match. Secondly, crazing is a widespread pattern cracks like crazy paving. Local crazing is due to heat around or from pouring hot fat into fiberglass sinks. More flexible gel coats were developed but brought problems like epidemic of blistering. Since then general crazing has become very uncommon, although there is evidence that it will be a feature of age and weathering.

Besides, applied delamination properly, gel coat forms a chemical bond with the moulding beneath. Any separation of the gel coat shows the bond very poor that probably due to contaminated interface, examples condensation, or delay so the waxy surface of some gel coats prevented good adhesion or wrong moulding technique. Moreover, pinholes are the gel coat is full of champagne sized bubbles and pinholes. Permeability will be high as water takes short cuts through the bubbles. A common reason for this is using cold gel coat brought in from outside storage. Other causes are over-vigorous stirring coupled with short setting time, a badly adjusted spray gun, or spraying in high humidity. Fig.
1 show the defect of pinholes and dust on the gelcoat surface.

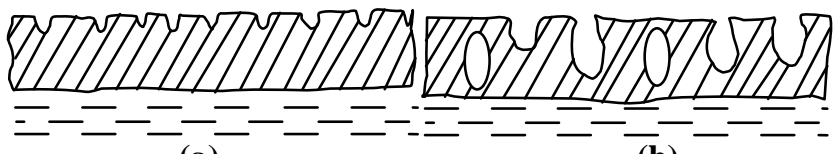

(a)

(b)

Fig. 1: An aerated gel coat causes (a) pinholes on the surface and tips of bubbles beneath, (b) dust on the mould leaves a similar appearance [35].

Furthermore, fisheyes are the spots of thin gelcoat surrounded by weak colour which are caused by the gelcoat have not wetting the mould surface due to wrong release agent or condensation on the mould and streaky colour. Brushing can induce colour separation. Colours can settle in the can so always stir before use. Colour pastes must be very well mixed otherwise the gel coat will be patchy or fade differentially. Along the waterline oil can be absorbed and form brown stains. Selective absorption or leaching forms patterns which sometimes resemble worms, and fuel interesting speculation. Speckles of different colours are common when two coloured gel coat is used for a boot top or styling flash due to overspray or drips settling on the adjoining part. Nothing can be done due to much part of the gel coat at rest. It may also be overspray from adjacent moulds or even paint. Table 4 show the various kind of defect detected, possibility causes, and suggested solutions

Table 4: Defect detected, possibility causes, suggested solutions [36].

\begin{tabular}{|c|c|c|c|}
\hline Image & Problem & Cause & Solution \\
\hline & $\begin{array}{l}\text { Blisters } \\
\text { (Catalyst Drop) }\end{array}$ & $\begin{array}{l}\text { Unreacted catalyst or } \\
\text { undercure }\end{array}$ & $\begin{array}{l}\text { Check catalyst percentage } \\
\text { additions, catalyst overspray, } \\
\text { mixing procedure and leaks }\end{array}$ \\
\hline & $\begin{array}{l}\text { Cracks } \\
\text { Reverse Impact }\end{array}$ & $\begin{array}{l}\text { Impact from laminate } \\
\text { side excessive gelcoat } \\
\text { thickness }\end{array}$ & $\begin{array}{l}\text { Check handling and } \\
\text { demoulding procedures. } \\
\text { Caution staff about } \\
\text { hammering on parts. }\end{array}$ \\
\hline & $\begin{array}{l}\text { Chalking } \\
\text { (degree of } \\
\text { chalking is related } \\
\text { directly to the } \\
\text { environment) }\end{array}$ & $\begin{array}{l}\text { Insufficient buffing } \\
\text { poor mould condition }\end{array}$ & $\begin{array}{l}\text { Wipe buffed area with } \\
\text { solvent rag. If gloss remains, } \\
\text { area is Ok. If gloss dulls, part } \\
\text { needs further buffing. }\end{array}$ \\
\hline
\end{tabular}




\begin{tabular}{|c|c|c|c|}
\hline & $\begin{array}{l}\text { Blisters } \\
\text { (Osmosis) }\end{array}$ & $\begin{array}{l}\text { Solvent, water or oil, } \\
\text { water blisters, air } \\
\text { pockets }\end{array}$ & $\begin{array}{l}\text { Check air lines, material and } \\
\text { rollers. Check rollout } \\
\text { procedure }\end{array}$ \\
\hline & $\begin{array}{l}\text { Porosity } \\
\text { (Magnified 10x) }\end{array}$ & $\begin{array}{l}\text { Entrapped air } \\
\text { excessive mixing } \\
\text { catalyst }\end{array}$ & $\begin{array}{l}\text { Wrong air pressure. High } \\
\text { pressure is fine porosity. }\end{array}$ \\
\hline 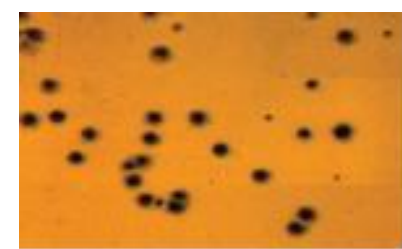 & Fisheyes & $\begin{array}{l}\text { Dust or dirt on mould } \\
\text { low viscosity material }\end{array}$ & $\begin{array}{l}\text { Low viscosity material } \\
\text { Water, oil or silicone } \\
\text { contamination }\end{array}$ \\
\hline 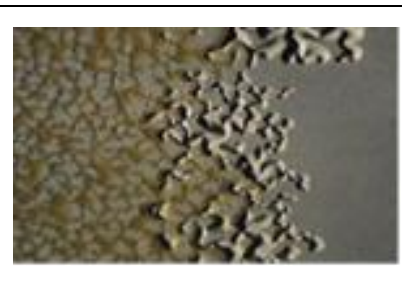 & $\begin{array}{l}\text { Alligatoring } \\
\text { (Tripe) }\end{array}$ & $\begin{array}{lr}\text { Raw catalyst solvent } \\
\text { thin } & \text { gelcoat } \\
\text { insufficiently } & \text { cured } \\
\text { gelcoat } & \text { before } \\
\text { laminating } & \end{array}$ & $\begin{array}{l}\text { Check for leaks or overspray. } \\
\text { Do not reduce product with } \\
\text { solvents. } \\
\text { Catalyst too high/low. } \\
\text { Temperature too low. Gel } \\
\text { time too long. Insufficient } \\
\text { time between coats. }\end{array}$ \\
\hline
\end{tabular}

\section{GELCOAT THICKNESS MEASUREMENT}

There are two tools able to measure the gelcoat thickness which are wet film thickness gauge and ultrasonic coating thickness gauge.

\subsection{Wet Film Thickness Gauge}

Altex Coating Industrial [37] have proposed wet film thickness reading are used to aid the painter and inspector in determine how much material to apply to achieve the specified wet film thickness as shown at Fig. 2 (a). The notch type gauge consists of two end points on the same plane with progressively deeper notched steps in between as shown at Fig. 2 (b). Each step is designed by a number representing the distance in microns between the step and plane created by the two end points. The instrument is pressed into wet film perpendicular to substrate and then withdrawn. The two end points will be wetted by the coating material, and some of the steps in between. The wet film thickness is considered as being between the last wetted step and the next adjacent higher dry one. If none of the steps or all of the steps in between the end points are wetted, it is necessary to turn the gauge to a different face, as the wet film thickness outside of that particular range.

\subsection{Ultrasonic Coating Thickness Gauge}

Hinojasa [38] suggested high accuracy method to determine gelcoat thickness is with a device that utilizes monopolar, magnetic induction. When magnet contact with a bare magnetic metal surface such as iron or steel plate place under the gelcoat will created a magnetic flux circuit. When the nonmagnetic coating sample like gelcoat is placed between the probe and plate, a gap in the magnetic flux is created. The difference in the magnetic flux is proportional to the coating thickness. These types of coating thickness gauges measure the difference in flux intensity to provide an accurate indication of coating thickness as shown at Fig. 3.
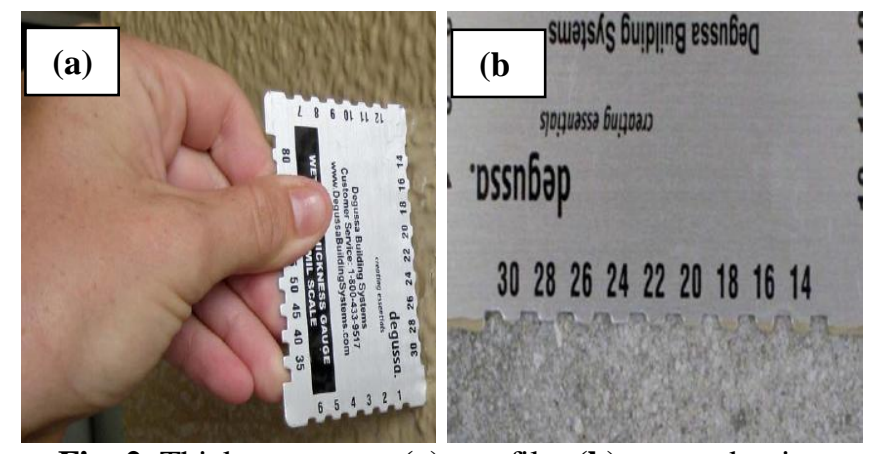

Fig. 2: Thickness gauge (a) wet film (b) two end points [38]. 


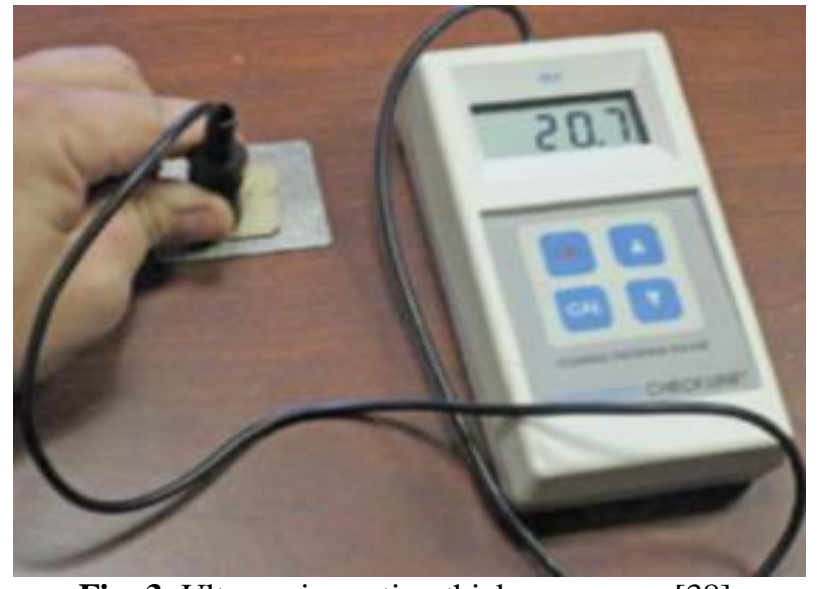

Fig. 3: Ultrasonic coating thickness gauge [38].

\section{PERFORMANCE OF LAMINATED COMPOSITE COVER BY GELCOAT}

As highlighted by Nguyen [39], the potential use of fiber reinforced polymer composites in modern façade systems, with a special focus on their fire performance. Gelcoat covering the surface of the thermoset composites. The gelcoat also provides a smooth and uniform appearance for the composite facade. The current pressing issue that prevents the application of FRPCs in facade systems lies in their fire performance. The debonding agent was first applied on the inner surface of a mould followed by a pigmented gelcoat using spray gun to give high quality surface finish. The result shows the percentage moisture absorption and void content increases with increase fiber length at constant fiber loading. The tensile strength, tensile modulus and percentage elongation of the composite attained a maximum in composite fabricated from fiber length. The compressive strength increases where impact energy decreased with increasing fiber length stated by Sumaila [40].

In fact of the burning behavior of a resin may result in other properties being adversely affected, and it is important to bear this in mind when choosing a resin system to meet specific fire performance criteria, for instance, laminates made using low fire hazard resins generally have poorer weather resistance than normal laminates, so they need the protection of a quality gel coat if they are to be used externally is agreed by Malik [41]. Similarly, Scudamore [42] state the presence of a gel coat on the polyester and epoxy products had some effect, mainly in the fiber reinforce grades. The fiber reinforce polyester with a brominated flame retardant showed a marked decrease in rate of heat release and in rate of smoke production.

The study of Yasar [43] was tensile and fatigue behavior of glass fiber-reinforced polyester automotive composite was investigated experimentally. The composite utilized as a part of this study comprises of fiber, polyester and gelcoat. Polyester and gelcoat contents were changed. It is clearly demonstrated that polyester content is the determinative factor for fatigue strength, while both gelcoat and polyester contents are effective for tensile strength. Optimum tensile strength was achieved according to the results shown and the fiber ratio was remain unchange in the particular mixing of polyester and gelcoats. It is believed that the blending of 52.14 wt.\% polyester and 9.75 wt.\% gelcoats can be a preferable way for designs requiring the best tensile and fatigue strength properties at the same time.

Scholz [44] presented a comprehensive review of surface coatings that are load-adapted and suitable for economical manufacturing are required for fiber-plastic composites subjected to complex loads. They consist of good wear and chemical resistance compared to conventional thermoset coatings like paints and gelcoats that high failure strain and adhesive strength. Polymeric nano-composites offer particular advantages in this respect. The main aim of this work is to characterize and evaluate surface-protection layers made of metal oxide nanoparticle reinforced epoxy gelcoats for tribological, mechanical and media loaded fiber-reinforced plastics.

\section{REVIEW SUMMARY}

This paper have gathered related information and references related to this research and including the theory aspect as guidelines to study the effect of gelcoat thickness on laminate composite structure and strength. Based on data recorded on Fig. 4, decision will be made to choose the best method. The fabrication process for gelcoat material and the physical properties with performance of the gelcoat with composite structure also raise in this review. By going through the research of various scientist and researcher from previous year, there are no much article or research discuss on the aspect of gel coat thickness on laminate composite. This have proved that, there are many factors need to be consider if wanted to produce a good surface and long service period product. Gelcoat have used in many sector start from household equipment to military submarine. Firstly, the main function of gel coat is provide a highquality finish on the visible surface of a fiber-reinforced composite material typically $0.5 \mathrm{~mm}$ to $0.8 \mathrm{~mm}$ thick. Due to there are no specified standard to verified that how much thickness required to produce certain product so the thickness data shown are the common thickness applied to related product. Secondly, comparison in gel coating process and type of resin base for gelcoat, mostly shown that spray up process is better process due to maintain the better quality finishing surface of gel coat but the considering aspect like cost and possibility cause defect need to be well planning, for example like keep the spraying gun clean after using will prevent the gelcoat remain in the spray gun curing and stuck at the nozzle while also have discuss polyester gelcoat are better than epoxy resin. 


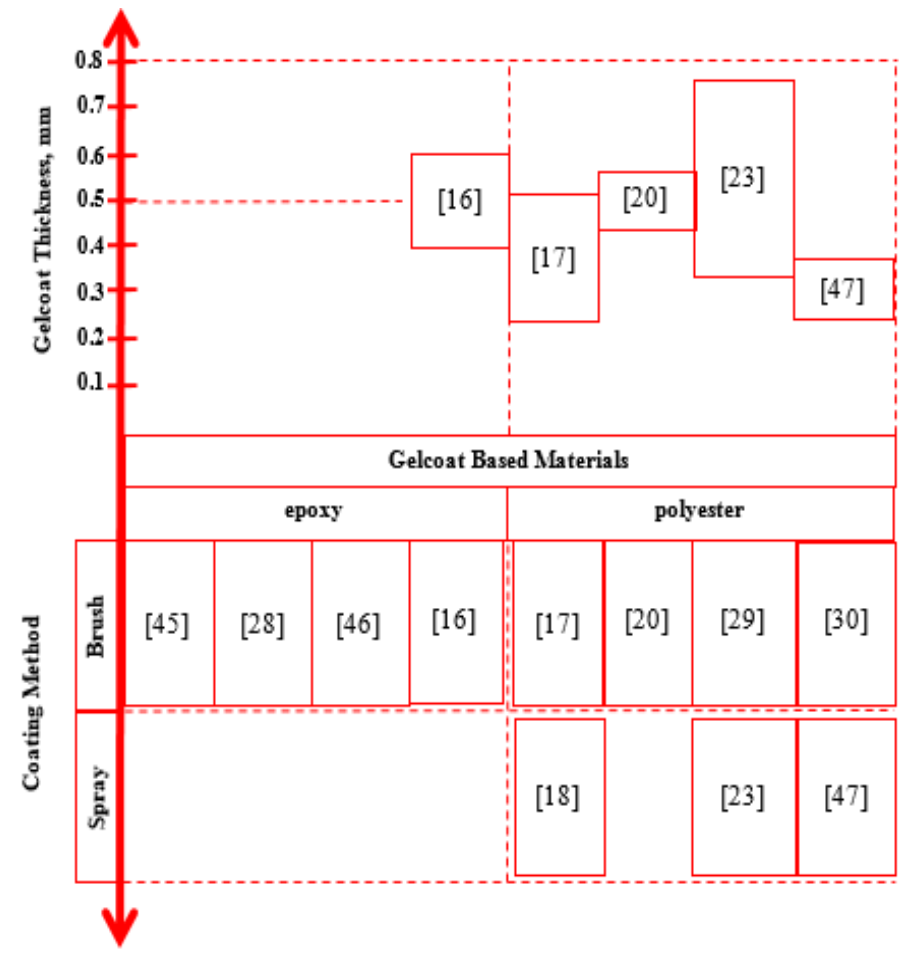

Fig. 4: Overview study on the literature review.

Besides, data collected on testing specimen show that the tensile test and flexural test is the most appropriate test. Tensile and flexural are common tests and fully standardized to determine how the material will react to external forces being applied in tension and bending fluctuating. Theory of interface or interphase needed to determine the bonding in between gel coat and laminate composite. The main advantage of a flexural test is the ease of the specimen preparation and testing. In term by needed to invent the strength performance of the typical gelcoat thickness on laminate composite is needed to consider the load transfer between interface of gelcoat and composite with desire testing method.

\section{CONCLUSION}

From the comprehensive review on the gelcoat used in laminated composite structure finished, a few points can be concluded as follows.

(a) Proper thickness applied on the surface of composite product might achieve their highest strength when the bonds between layers of fiberglass and gelcoat strongly bonded.

(b) Scientific information and deep understanding on the role of catalyst in the curing behavior and performance of gelcoat is extremely required before do the mixing process.

(c) The knowledge on role of gelcoat used in laminated system need to be proved experimentally in order to develop a new idea by control the gelcoat thickness to enhance composite product with using standard amount of catalyst to design a better product.

(d) The dependency to use less corrosive catalyst material that suitable to environment and enhance the performance of gelcoat on laminated composite strength such as polyether ether ketone, acetyl- acetone peroxide, vinyl polymerization peroxide, benzoyl peroxide that are commonly used in the gelcoat.

\section{REFERENCES}

[1] Paluvai, N.R., Mohanty, S. and Nayak, S.K. (2015), Studies on thermal degradation and flame retardant behavior of the sisal fiber reinforced unsaturated polyester toughened epoxy nanocomposites, J. Appl. Polym. Sci., 42068. doi: 10.1002/app.42068

[2] Qiu, R., Ren, X., Fifield, L. S., Simmons, K. L. and Li, K. (2011), Hemp-fiber-reinforced unsaturated polyester composites: Optimization of processing and improvement of interfacial adhesion, J. Appl. Polym. Sci., Vol.121, Iss.2, pp.862-868, doi: 10.1002/app.33674

[3] Karapappas, P., Tsotra, P. and Scobbie, K., (2011). Effect of nanofillers on the properties of a state of the art epoxy gelcoat, eXPRESS Polymer Letters, Vol.5, No.3, 218-227.

[4] Scholz, S., Kroll, L. and Schettler. F. (2014). Nanoparticle reinforced epoxy gelcoats for fiberplastic composites under multiple load, Progress in Organic Coatings, Vol.77, Iss.7, pp.1129-1136.

[5] Keegan, H.M., David, N. and Margaret, S. (2013). Numerical modelling of hailstone impact on the leading edge of a wind turbine blade, EWEA Annual Wind Energy Event 2013, Vienna.

[6] Yardimcia, A.I., Tanoglub, M. and Selamet, Y. (2013). Development of electrically conductive and anisotropic gel-coat systems using CNTs, Progress in Organic Coatings, Vol.76, Iss.6, pp.963-965.

[7] Washer, G. and Schmidt, J. (2014). Quality Control and In-Service Inspection Technology for HybridComposite Girder Bridges, Missouri University of Science and Technology.

[8] Mouritz, A.P. and Gibson, A.G. (2007). Fire properties of polymer composite materials, Springer Science \& Business Media, Vol.143, pp.279-280.

[9] Dong, C. (2009). Liquid resin, polymer solution and latex processing, Advances in polymer processing: from macro to nano scales, Cambridge, UK: Woodhead Publishing Ltd, pp.289-311.

[10] Gombos, Z. and Summerscales, J. (2014). In-mould gel-coating with a separator layer. Advanced Composites Manufacturing Centre, School of Marine Science and Engineering, Plymouth University, pp.37.

[11] Landowski, M., Budzik, M. and Imielińska, K. (2014). Water absorption and blistering of glass fibre-reinforced polymer marine laminates with nanoparticle-modified coating, Journal of Composite Materials, Vol.48, No.23, pp.2805-2813.

[12] Salit, M.S. (2014). Manufacturing Techniques of Tropical Natural Fibre Composites, Tropical Natural Fibre Composites Engineering Materials, pp.103118.

[13] Raghavendra, N., Murthy, H.N.N., Krishna, M., Mahesh, K.R.V, Sridhar, R., Firdosh, S., Angadi, G. and Sharma, S.C. (2013). Mechanical behavior of 
organo-modified indian bentonite nanoclay fiberreinforced plastic nanocomposites, Frontiers of Materials Science, Vol.7, Iss.4, pp.396-404.

[14] Borsting, D.A., Zhou,Q., Van, D.Z.J.J. and Rajamani, R. (2010). Method of applying gelcoat and an arrangement performing said method, Application, Publication number WO2010055061 A1.

[15] Fiber Glass-Evercoat Corp, (2000). Gel coat - Basic Information, Division of Illinois Tool Works Inc.

[16] Lacovara, B. (2010). Get wise to gel coat cracks: characterizing crack defects, Convergent Composites, American Composites Manufacturers Association, pp.1-8.

[17] Saltz, W.T. (2009). Bay area air quality management district. Bay Area 2005 Ozone Strategy Control Measure SS-4BAAQMD Regulation 8, Rule 50: Polyester Resin Operations.

[18] Wright, J. (2004). Polyester over epoxy, Gougeon Brothers, Inc. EPOXYWORKS, No.22, pp.1-2.

[19] West System Brand, (2008). Gelcoat blisters-repair, diagnosis \& prevention. Gougeon Brothers, Inc. Product Catalog No.002-650.

[20] Summerscales, J., Hoppins, C., Anstice, P., Brooks, N., Wiggers, J., Yahathugoda, D., Harper, A., Wood, C. and Cooper, M. (2010). In-mould gel coating for resin transfer moulding, The 10th International Conference on Flow Processes in Composite Materials.

[21] Makarov, V.G. and Sinelnikova, R.M. (2011). Crack formation in chemically resistant glass-fiber reinforced plastic pipes, Chemical and Petroleum Engineering, Vol.47, Iss.5-6, pp.409-412.

[22] BUFA Gelcoat Plus Corp. (2008). Technical information: working with OLDOPAL-Gelcoats, BUFA Gelcoat Plus GmbH \& Co. KG.

[23] Bauchet, F., Morris, L., Holley, W. and Seroogy, K. (2014). Polyester-polyurethane hybrid resin moulding compositions comprising polyurethane with units derived from aliphatic isocyanates, United States Patent, Patent No. US 8,742,054 B2.

[24] Derek, B., Thorvald, S. and Keeley, S. (2013). Rainbow rock. Ifi claims patent services, Publication number CA2762295 A1.

[25] Scott Bader Corp. (2005). Guidelines for application of spray gelcoat. Technical support report.

[26] Aird, F. (2006). Fiberglass and other composite materials HP1498, Penguin Group (USA) Inc., pp.40-44.

[27] Jawahar, P., Kanny, K. and Balasubramanian, M. (2013). Influence of nanoclay addition on properties of unsaturated-polyester nanocomposite gel coat system, Journal of Polymer Engineering, Vol.29, Iss.8-9, pp.563-580.

[28] Nielsen, M.W. (2012). Prediction of process induced shape distortions and residual stresses in large fiber reinforced composite laminates, Department of Mechanical Engineering Technical University of Denmark. (Ph.D. Dissertation).

[29] Osman, E. A., Vakhguelt, A., Sbarski, I. and Mutasher, S. A. (2012). Curing behaviour and tensile properties of unsaturated polyester containing various styrene concentrations, Malaysian Polymer Journal, Vol.7, No.2, pp.46-55.

[30] Kosar, V. and Gomzi, Z. (2001). Thermal effects of cure reaction for an unsaturated polyester in cylindrical moulds, Chem. Biochem. Eng. Q, Vol.15, No.3, pp.101-108.

[31] Mafia, R., Mirabedini, S.M., Attar, M.M. and Moradian, S. (2005). Cure characterization of epoxy and polyester clear powder coatings using Differential Scanning Calorimetry and Dynamic Mechanical Thermal Analysis, Progress in Organic Coatings, Vol.54, pp.164-169.

[32] Bauchet, F., Morris, L., Holley, W. and Seroogy, K. (2014). Polyester-polyurethane hybrid resin moulding compositions comprising polyurethane with units derived from aliphatic isocyanates, United States Patent, Patent No. US 8,742,054 B2.

[33] Beheshty, M.H., Hayaty, M. and Vafayan, M. (2006). Evaluation additives in the curing of unsaturated polyester resins, Iranian Polymer Journal, Vol.15, No.2, pp.143-153.

[34] Naqvi, S.N.E., Naveed, S., Javaid, S.H. and Ramzan, N. (2014). Enhancing the chemical and mechanical properties of UPR, Journal of Quality and Technology Management, Vol.10, Iss.1, pp.1-15.

[35] Plessis, H.D., (2013). Fiberglass boats: construction, gel coat, stressing, blistering, repair, maintenance. Bloomsbury Publishing, pp.160-162.

[36] CCP Composites Australia Corp. (2014). Gelcoat Troubleshooters Guide. CCP Composites Application Guide.

[37] Altex Coating Industrial. (2004). Use of a wet film thickness gauge, Application training manual $\mathrm{V}$ 1.0.1, pp.25-26.

[38] Hinojasa, R., (2009). Field testing of wet film thickness and dry film thickness of waterproof coatings, RCI Inc. pp.22-28.

[39] Nguyen, Q., Ngo, T., Mendis, P. and Tran, P. (2013). Composite materials for next generation building façade systems, Civil Engineering and Architecture, Vol.1, No.3, pp.88-95.

[40] Sumaila, M., Amber, I. and Bawa, M. (2013). Effect of fiber length on the physical and mechanical properties of random oreinted, nonwoven short banana (musa balbisiana) fiber9 /epoxy composite, Leena and Luna International, Oyama, Japan, Vol.2, No.1, pp.39-49.

[41] Malik, A.A., Yaacob, N., and Radzi. A.A. (2013). The effect of bi-carbon black (n660 \& n774) in polyester resin matrix for marine composite structure, International Conference on Emerging Trends in Engineering and Technology, pp.110-112.

[42] Scudamore, M.J. (2004). Fire performance studies on glass-reinforced plastic laminates, Fire and Materials, Vol.18, Iss.5, pp313-325.

[43] Yasar, A., Kacar, I. and Keskin, A. (2014). Tensile and Fatigue Behavior of Glass Fiber-Reinforced (MAT-8)/Polyester Automotive Composite, Arabian 
Journal for Science and Engineering, Vol.39, Iss.4, pp.3191-3197.

[44] Scholz, S., Kroll, L. and Schettler. F. (2014). Nanoparticle reinforced epoxy gelcoats for fiberplastic composites under multiple load, Progress in Organic Coatings, Vol.77, Iss.7, pp.1129-1136.

[45] Kumar, K.V., Reddy, P.R. and Shankar, D.V.R. (2013). Effect of angle ply orientation on tensile properties of bi directional woven fabric glass epoxy composite laminate, International Journal of Computational Engineering Research, Vol.3, Iss.10, pp.55-61.

[46] Raja, M.N. and Rao., A.N.H. (2013). Effect of an angle-ply orientation on tensile properties of kevlar/glass hybrid composites, Department of Mechanical Engineering, S.J College of Engineering, Mysore, Karnataka, India., Vol.2, Iss.3, pp.63-67.

[47] Tsuzuki, E.K., Taniguchi, C. and Filho, A.C. (2002). Gelcoat blistering and the use of glassflakes, International Offshore and Polar Engineering Conference, Kitakyushu, Japan, pp.185-191. 